University of Nebraska - Lincoln

DigitalCommons@University of Nebraska - Lincoln

PreColumbian Textile Conference VIII /

Jornadas de Textiles PreColombinos VIII (2019)

Centre for Textile Research

$6-2020$

Signos comunes en los textiles Andinos y los Mesoamericanos

Victòria Solanilla

Follow this and additional works at: https://digitalcommons.unl.edu/pctviii

Part of the Art and Materials Conservation Commons, Fiber, Textile, and Weaving Arts Commons, Indigenous Studies Commons, Latin American Languages and Societies Commons, Museum Studies Commons, and the Other History of Art, Architecture, and Archaeology Commons

This Article is brought to you for free and open access by the Centre for Textile Research at DigitalCommons@University of Nebraska - Lincoln. It has been accepted for inclusion in PreColumbian Textile Conference VIII / Jornadas de Textiles PreColombinos VIII (2019) by an authorized administrator of DigitalCommons@University of Nebraska - Lincoln. 


\title{
12
}

\section{Signos comunes en los textiles Andinos y los Mesoamericanos}

\author{
Victoria Solanilla \\ Universidad Autonoma de Barcelona
}

\section{Resumen}

Entre los recientes estudios sobre textiles Andinos, comienza a ser frecuente encontrar quienes se dedican a describir además de las técnicas, sus iconografías. Como eran sociedades ágrafas, nos hace pensar que con aquellas imágenes nos quisieron dejar su historia y pensamiento.

En el caso de Mesoamérica, se podría decir lo mismo de las técnicas e imágenes, pero en este caso, las sociedades que los tejieron sí tenían manera de comunicarse a través de sus lenguajes escritos. No se han conservado tantos tejidos a causa del clima por las condiciones no favorables para la conservación de materiales orgánicos, pero tenemos muchos ejemplos de figurillas de cerámica, de piedra o de grandes esculturas que nos muestran cómo iban vestidos y por lo tanto, como eran sus tejidos.

Esta ponencia pretende estudiar los casos de imágenes tejidas que se encuentran en ambas zonas geográficas y su significado.

Palabras clave: Textiles, Mesoamérica, Zona Andina, Iconografía, signos comunes.

\section{Abstract}

It is increasingly common to find recent studies on Andean textiles that look further past weaving techniques and that interestingly dig into iconography and their descriptions. The fact that Andean civilizations were preliterate suggests that these iconographies were meant to bequeath both their history and thought to succeeding generations.

Interestingly, some similar weaving techniques were found in Mesoamerica. And again we find the same intent in their images, even though they did have an alternative way of communicating through their written alphabets.

Not many Mesoamerican textiles have made it to the present day due to their location and climate. Still, a large number of ceramic figurines, stone figurines and larger sculptures have been found, which depict how their people dressed and subsequently what their textiles looked like.

This presentation aims to present a number of woven images found in both geographical areas (Andean and Mesoamerican), their iconographies and common traits.

Keywords: textiles, Mesoamerican, Andean zone, iconography, common traits

\section{Résumé}

Dans les récentes études sur les textiles andins, il est maintenant fréquent de trouver celles qui se dédient à décrire en plus des techniques, l'iconographie. Comme il s'agit de sociétés sans écriture, cela nous fait penser qu'à travers ces images ils ont voulu nous laisser leur histoire et leur pensée.

Dans le cas de la Méso-Amérique, nous pouvons dire la même chose des techniques et des images, mais dans ce cas, les sociétés qui les ont tissés avaient aussi comme moyen de communication leurs textes écrits. Peu de textiles ont été conservés à cause des conditions non favorables pour la conservation des matériaux organiques, mais nous avons de nombreux exemples de figurines en céramique, en pierre et de grandes sculptures qui nous montrent comment ils étaient revêtus et du moins comment étaient leurs tissus.

Cet article prétend étudier les cas des images tissées qui se trouvent dans les deux zones géographiques et leur sens.

Mots-clés: Textiles, Méso-Amérique, zone andine, iconographie, traits communs. 


\section{Introducción}

Los estudios actuales de textiles Andinos, se dedican a describir además de las técnicas con las que estaban hechos, sus iconografías. Si el primer punto es importante para saber los diversos tipos de técnicas textiles, el segundo no lo desmerece puesto que nos indica cómo era el mundo terrenal o el sobrenatural que los rodeaba. Al ser sociedades ágrafas, nos hace pensar en que con aquellas imágenes nos han querido dejar parte de su historia y pensamiento.

En Mesoamérica, se podría decir lo mismo de las técnicas e imágenes, pero en este caso, las sociedades que los tejieron si tenían manera de comunicarse a través de sus lenguajes escritos. A causa del clima y las condiciones no favorables para la conservación de textiles, no se han conservado tantos tejidos, pero tenemos muchos ejemplos de cómo vestían en figurillas de cerámica, de piedra o de grandes esculturas, así como en los dibujos de los Códices indígenas que nos muestran cómo iban vestidos y por lo tanto, como eran sus tejidos. (Filloy, 2017:7).

La región andina durante el largo proceso de desarrollo sociocultural logró amalgamar un extenso campo ideológico, que comportó la aparición desde períodos muy tempranos (período Arcaico Temprano: 8500 A.P. aprox.) de una religión consolidada, con un panteón politeísta, basada en la veneración de múltiples dioses de carácter naturalista, cuya máxima expresión, ya desde el Arcaico Tardío, se centró en el culto al dios de los báculos, ampliamente expandido por la cultura Chavín (período Formativo, 2000-500 a.C.), representado por la trilogía: aire (águila- arpía), agua (caimán) y tierra (serpiente y jaguar) ${ }^{1}$. Se sabe que esta divinidad «modernizada» aparece luego en la Portada del Sol de Tiahuanaco, para hacerlo más tarde en el Tahuantinsuyu, convirtiéndose en Wiraqocha. Era la divinidad universal.

Sin embargo, además de estas divinidades existían muchas otras de carácter regional, que eran adoradas en grandes extensiones territoriales, abarcando el ámbito de varias culturas. Entre estas tenemos a Pachacamac en la costa central, y Pariacaca, dios de la lluvia, entre muchas otras.

El sistema de culto religioso estuvo a cargo de un cuerpo jerárquico de sacerdotes andinos, encargados de dirigir el culto a huacas, santuarios, ídolos, mallquis, etc. Entre este cuerpo especializado de sacerdotes, se encontraron personajes de múltiples orígenes que consiguieron llevar a cabo toda una serie de rituales dirigidos a sus dioses, en los que los tejidos eran motivo principal.

Este mismo relato, se podría aplicar a las culturas de Mesoamérica, puesto que su cosmología también se centra en tres ámbitos verticales, como en los Andes: cielo, tierra e inframundo, con seres animados (animales) que habitaban estas zonas. La interacción entre los Mesoamericanos fue de naturaleza económica, política, religiosa y también cultural. De esta última surge una tradición cultural común, formada por Olmecas, Teotihuacanos, Mayas, Zapotecas, Mixtecas, Toltecas y finalmente Mexicas, que se dieron en tiempos y lugares distintos de Mesoamérica. Poseyeron pues una visión del mundo, religión y mitología comunes. También se inició en momentos tempranos como decíamos más arriba de la Zona Andina, hacia el 6500 AC cuando se comenzó a domesticar el maíz y a iniciar la agricultura. Cada cultura pues, mantendrá sus principios durante largos períodos de tiempo, que se repetirán como patrones normativos de los que muchos de ellos llegarán hasta nuestros días.

Viendo las diversas cosmovisiones y mitologías mesoamericanas, nos damos cuenta de que debemos tener una actitud abierta hacia un universo animado, en el que todo tipo de seres vivos, los elementos del paisaje y los fenómenos naturales están embebidos de un poder o fuerza invisible. Esta fuerza puede ser amorfa, pero a veces puede estar personificada en una deidad particular, que puede tomar forma humana o animal. Tomando una cita de SHARER (1994:514) nos dice:

\section{"El mundo es considerado un espacio ordenado y el orden se deriva de los movimientos previsibles de los astros que marcan el paso del tiempo. Los cuerpos celestes y el tiempo mismo, se conside- ran animados. El destino humano está ligado al de los cuerpos celestes".}

Por lo tanto, cuando el hombre toma algo de la naturaleza, debe dar algo igual a cambio. Respetar a los dioses (ofrendas, alabarlos y apaciguarlos si llegara el caso). Es a través el rito y las ceremonias que lo consigue; gracias a la acción de los sacerdotes.

Y en el caso de Mesoamérica, los dioses creadores que aparecen en los Códices tejiendo, explica claramente "el carácter primigenio y axial del acto de tejer. Y Tejer, en su dimensión simbólica, es una acción fundacional. A través del tejido, los dioses crean y dotan de orden el mundo" como afirma Alberto MORALES (2009:98).

Observando los diversos materiales de ambas zonas (textiles, cerámicas, esculturas...) se pueden apreciar signos que se repiten a ambos lados del continente Americano. Este hecho hace pensar pues en una relación entre ambas partes. Rieff Anawalt (1992:114) afirma que:”

1. Beatriz Barba de Piña Chan (Coord.)(200o) “Iconografía mexicana II. El cielo, la tierra y el inframundo: águila, serpiente y jaguar”. INAH. En esta publicación, se recogen una serie de artículos sobre esta temática, que se presentaron en el Seminario de Iconografía Mexicana, organizado por la UNAM y el INAH. 
El estilo del vestido, los diseños decorativos $y$ las técnicas de producción ilustrados en los códices, la cerámica y en fragmentos de tejidos, sugieren la difusión de elementos culturales de la costa norte de Sudamérica a la parte oeste de México y al suroeste de los Estados Unidos. Los trajes de origen no-mesoamericano ilustrados en un manuscrito del siglo dieciséis (relación de Michoacán), proveniente del oeste de México, y los mostrados en figuritas depositadas en tumbas más de un milenio antes, tienen parecido con los estilos del vestido presentes en Ecuador desde 1500 A.C. hasta el momento del contacto con los Españoles. La ropa y los diseños decorativos representados en las tumbas en forma de bota de Ixtlan del Rio, en Nayarit, indican que estos paralelos existían tan temprano como 400 A.C. Otra información diversa sugiere que hubieron persistentes contactos marítimos entre el Ecuador y el oeste de México durante todo este período y que continuaron hasta el siglo dieciséis”

A partir de esta rotunda afirmación de Anawalt, encontramos otros estudiosos que trataron este tema de las relaciones prehispánicas entre el norte de Suramérica y el oeste de México, vía Pacifico. ${ }^{2}$

\section{Signos comunes}

EL MEANDRO ESCALONADO (Zona Andina) (TIERRAAGUA). XICALCOLIUHQUI (Mesoamérica) (fig. 1)

xicalcoliuhqui. (Voz náh., de xicalli, jícara y coliuhqui, torcido, curvo). Mit. V. Greca escalonada...

Fray Bernardino de Sahagún comenta que el Xicalculiuhqui es uno de los motivos que lucen las faldas de las mujeres nobles ${ }^{3}$. También encontramos otro testimonio en el Códice Magliabechiano 4 de una manta con esta figura. El escribano dice: "Manta de xícara tuerta".

Beyer (1924:80) en su estudio específico de la greca escalonada dice: "Respecto a riquezas y hermosura de las formas, el meandro mexicano no pide favor al griego; hasta se puede afirmar que éste tiene un aspecto severo, rígido, frío, en comparación con el ornamento mexicano, de carácter

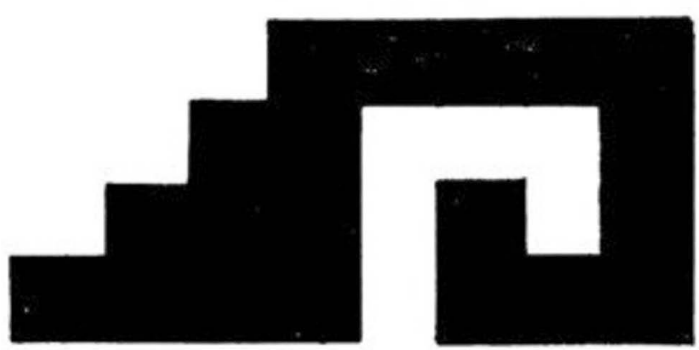

Figura 1. Meandro escalonado (Zona Andina). Chavin (hasta 8ooaC.). (con permiso de U. Carlson 2010:8).

más suave y ameno". Es curioso que este autor no hable de su significado sino de cómo fue hecha, escultóricamente. Para él fue un mero elemento ornamental. Aceptó una cierta significación en la época Preclásica, pero a medida que se avanzó en el tiempo, se convirtió en un elemento puramente decorativo (Postclásico).

En cambio, Caso (1992:37) en su estudio completísimo de este signo afirma:

"La greca escalonada es para la plástica prehispánica lo que el capitel para la cultura griega, o el arco ojival para el arte gótico. Es un símbolo que se ha encontrado desde Arizona en los Estados Unidos de América, hasta Perú y Argentina en el sur del continente."

Y esta afirmación refuerza nuestra creencia de que hay signos en Amerindia que son comunes a todas las partes. También dice que su significado es diverso, de las más sencillas (serpiente estilizada o corte transversal de un caracol marino) a las complejas (ideas cosmológicas). Pero Caso termina afirmando que para él, la greca escalonada representa en sí misma una dualidad de elementos antagónicos, la escalera y la espiral, que son opuestos polares inseparables como los polos de un imán o las caras de una moneda.

En un completo estudio sobre los diseños que se encuentran en la vestimenta de las "figuras sonrientes" de la Costa del Golfo, (Huckert 2006: 112-116) documenta principalmente la greca escalonada y la clasifica en cuatro tipos diferentes, según la distribución o modelo de las mismas en

2. Meighan: 1969 design motifs; Swadesh: 1967 language; Lapiner 1976:344. Donde cita gran cantidad de figuras humanas de cerámica encontradas en Los Esteros (Costa de Ecuador, fase Bahia (500 B.C.-100 A A.D.) . Afirma que estas esculturas huecas, llevan pendientes de múltiples anillos, como los que llevan las figuras de Ixtlan del Rio. Y también habla de otros paralelos, en las decoraciones geométricas que representan telas policromas, y en las formas y decoraciones de las faldas.

3. Primeros Memoriales (1993), fol.56r; 1997:205. Xumoiuiuipilli xicalculiuhqui cueitl quinamiqui: "Blusa de pluma de pato y falda con el diseño del meandro escalonado"

4. (1970, fol.6) 
las faldas. Hace referencia a la calabaza en forma de botella que riega y fertiliza, así como a seres ofidios celestes y acuáticos y también a figuras de agua. ${ }^{5}$

Respecto a la difusión que ha tenido este símbolo del meandro escalonado en la Zona Andina, tenemos muchos ejemplos de todas las diversas culturas que formaron parte de esta región durante muchos siglos. Parece que su plasmación fue en la zona septentrional andina, mostrándose sobre la base de estos dos elementos con gran variedad de representaciones: en forma dual o múltiple, relacionadas directamente con la imagen de la divinidad o solas, y formando patrones concretamente en los textiles. (Fig.2)

En el estudio de las piezas de la Colección Maiman ${ }^{6}$ en el vol.I de la Catalogación, se puede ver representado este

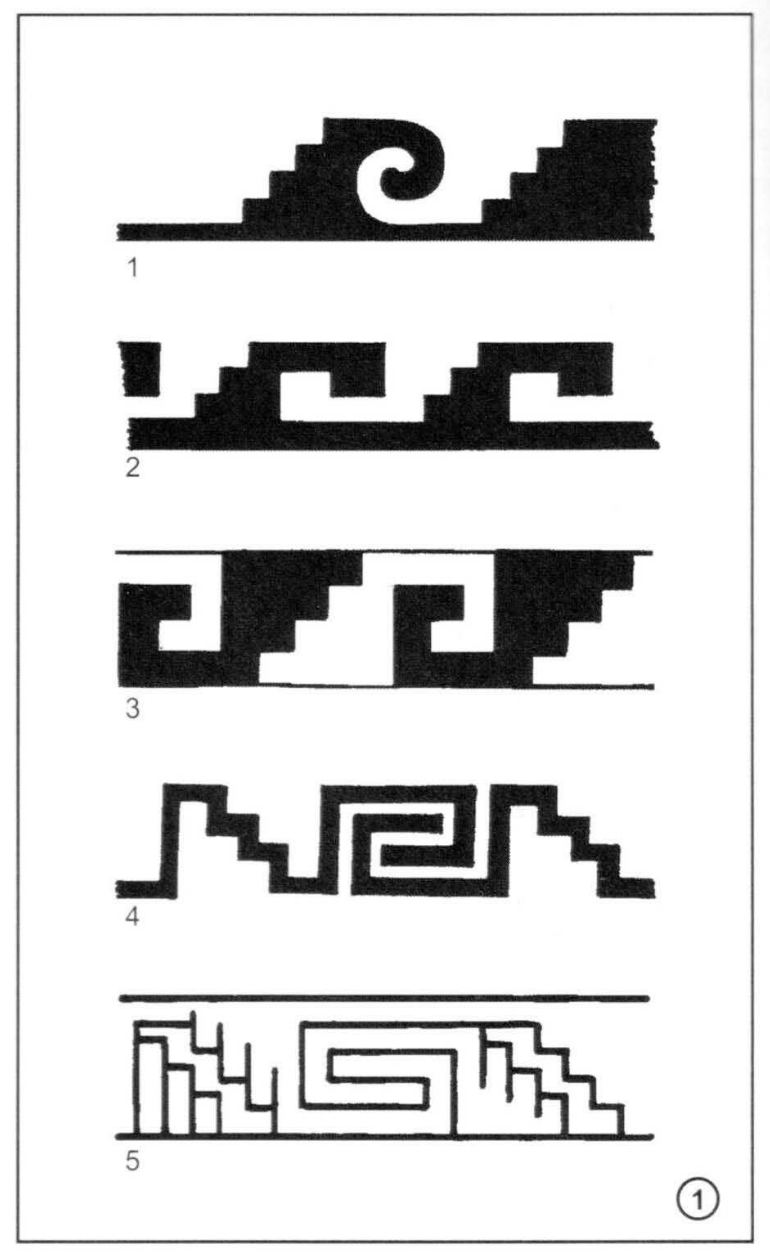

Figura 2. Difusión meandro escalonado en la Zona Andina. 1. Decoración mural, Huaca Choltuna, Lambayeque. 2. Tejido Moche. 3. Tejido Pachacamac. 4. Cerámica Recuay. Cerámica Nasca. (Con permiso de U. Carlson 2010:10). signo (stepped frets) en el período Intermedio Temprano (2006:71)-Moche; Horizonte Medio (2006:106)-NazcaHuari; en el Periodo Intermedio Tardío (2006: 132)Lambayeque con influencia Chimú; Chimú Antiguo (2006: 144); Chimu-Inca, estilo Pelícano (2006: 165).

Laurencich Minelli (1984:55/1984:138). Intermedio Tardío. Costa Centro-septentrional. Les llama "voluta escalonada". (1984:136) en que se ve una pequeña bolsa que tiene como motivo decorativo una única greca escalonada que ocupa toda su superficie.

Uwe Carlson ((2010:9) afirma que Kauffmann Doig "presume que en Mesoamérica estos signos (tierra/agua) pudieron tener igual significado que en el Perú" porque en aquella zona también se luchaba por la subsistencia de manera importante, ya que las lluvias eran cada vez menos frecuentes debido a la deforestación cada vez mayor de los bosques y porque aquel territorio tiene áreas claramente poco propicias para la agricultura.

Representa pues la fertilidad: forma escalonada -terrazas de cultivo (andenes) que se combina con la ola estilizada. Sobre este aspecto, volvemos a citar a U. Carlson (2010:11) donde dice que" este símbolo o en ocasiones una parte, se convirtió en un símbolo de identificación y en una característica”. Y añade que con su ayuda es posible interpretar una gran cantidad de representaciones en los tejidos. (Fig. 3)

Un estudio de Carlson (2014:11) propone que el meandro-escalonado de las cerámicas Chavín se representó hasta aproximadamente el 800 a.C. y representaba el simbolismo religioso. Y más tarde, a criterio de los sacerdotes y puesta en práctica por los artistas, pasó a primer plano el simbolismo del meandro-serpiente. Y desde esta cultura Chavín

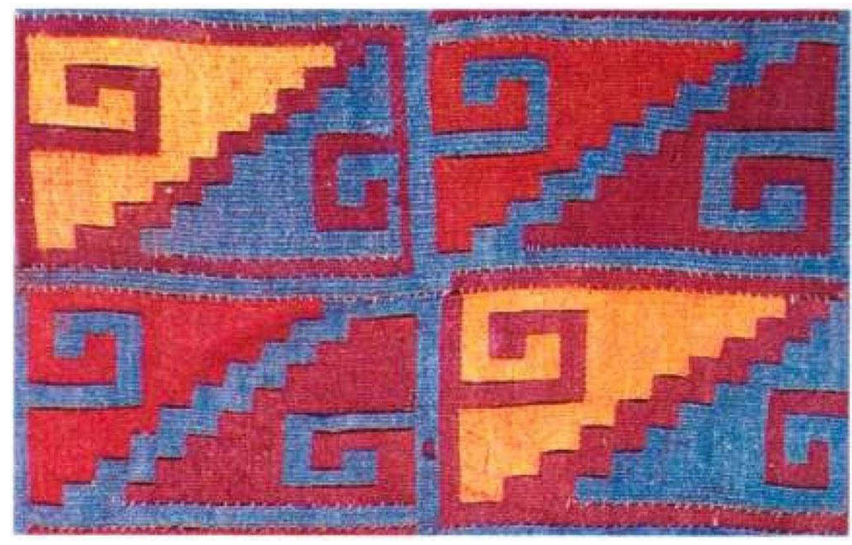

Figura 3. Forma escalonada = terrazas de cultivo. Más la ola estilizada. (Con el permiso de U. Carlson 2010: 19/ 2010:22/ 2010:47).

5. Códice de Madrid (1970: fol.3ob). Diosa O, demiurga maya de las lluvias. Viste una falda diseñada con bandas de agua y el diseño del Xicalcoliuhqui.

6. Makowski K, Rosenzweig A , Jiménez M.J. Weawing for the Afterlife (2006) 
que aplicó claramente los dos tipos de meandro correlativamente, se produjo una diáspora a otras culturas posteriores. (Fig. 4).

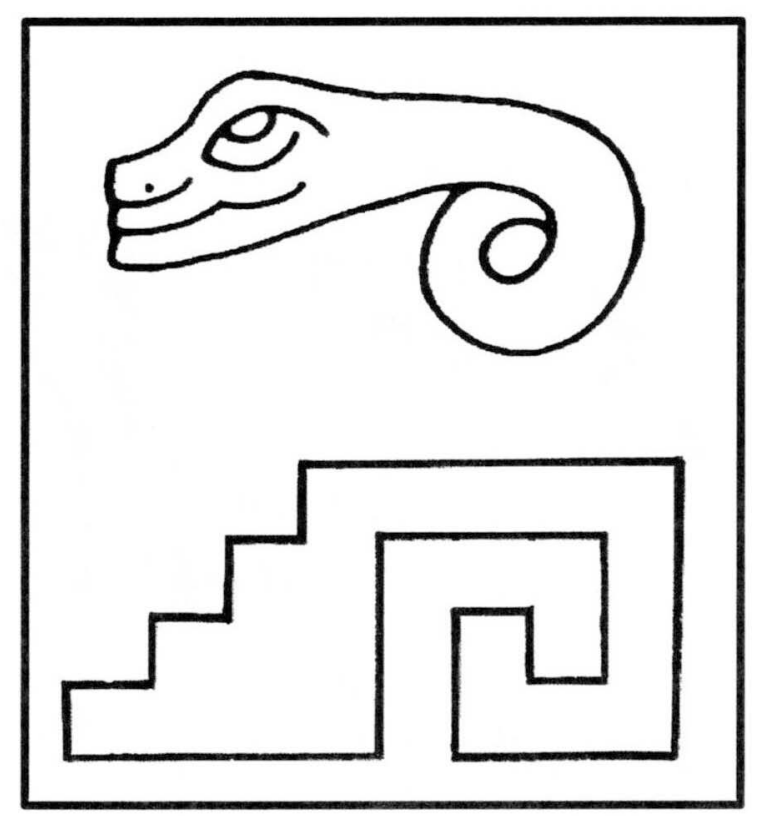

Figura 4. Meandro escalonado-meandro serpiente. (Con el permiso de U.Carlson 2006:11 )

\section{Simbolo de la "S" horizontal (nube)}

De este signo, encontramos muchos ejemplos en ambas zonas: tanto en Mesoamérica (en figurillas, pinturas murales y códices, principalmente) como en la Zona Andina (textiles).Puesto que eran culturas que tenían la agricultura como principal sustento, es lógico que con este diseño pidieran a sus dioses, la llegada de la lluvia que les fertilizara sus campos.

Podemos dar varios ejemplos que sustentan esta teoría.

Glifo maya “muyal” (nubes). Las formas en S desde el Preclásico Medio, describen nubes. Relieve 1 de Chalcatzingo. "Señor de la Tierra" o ·Señor del Cerro" (Montoya 2003:110).que es un grabado de tamaño natural en el que se observa a un hombre sentado en el interior de una cueva. El punto de vista de la escena es lateral, de modo que la caverna es representada más bien por un corte transversal que, además, es la representación de las fauces de un jaguar. La entrada a la cueva se localiza frente al personaje sedente, a la derecha de la imagen. De ella salen volutas (quizá indicando que el hombre está hablando o haciendo alusión al viento). Sobre la caverna se encuentran representados unos objetos estilizados que parecen ser nubes, de ellas caen gotas de agua. En la cueva, una persona con gran tocado se ubica en un trono de piedra. Sostiene un objeto rectangular con volutas (eses horizontales) con ambas manos, frente al pecho. Esta actitud se encuentra con frecuencia en representaciones olmecas.

En el glifo 632 del Códice Trocortesiano (D. Dupiech Cavaleri, 2016:201) afirma que la "S" también aparece como afijo del glifo del sol y del cielo. Dice que son nubes que traen la lluvia y fertilizan la tierra

En las "Bandas celestes” que aparecen en los bordes de los huipiles de las damas de la corte en monumentos del Período Clásico"( Montoya 2008:113)se encuentran diversos diseños entre los que está el "motivo nube" y la "Voluta (greca) escalonada). Principalmente en las estelas y dinteles de Yaxchilán. Están formando el marco de una escena. Lo envuelven. Ejemplo: la lápida funeraria de Pakal. Estas imágenes que forman la banda, adornan el cuerpo de la serpiente cósmica, estaban divididas en segmentos decorados con diversos símbolos entre los que se encuentran los antes citados. (Schele \& Miller, 1992:t282).

\section{Grecas en espiral}

Makowski et alt.(2006:192-193). Las grecas en espiral pueden representar las olas del océano, dibujadas frecuentemente en el arte de la Costa Norte del Perú.

\section{Animales}

\section{Los animales en la cosmovisión mesoamericana y andina}

El hombre de las sociedades antiguas (cazadores, pastores o agricultores) consideraba que los animales tenían una relación especial con lo divino, lo que les concedió un lugar importante en los mitos y en las leyendas; los convirtió también en representaciones de las ideas fundamentales de la cultura. Esta visión prevalecía en toda Mesoamérica y también en la Zona Andina.

Toda la iconografía mesoamericana está llena de figuras de animales que aparecen completos, solos o con algunos de sus elementos, como pueden ser las garras, la cabeza o las orejas, que aportan ciertas características a los dioses o a lo que están transmitiendo. Esta tendencia a tomar como fuente de inspiración las cualidades que tienen o se atribuyen a los animales es universal.

Es indudable que son precisamente los animales que comparten el hábitat de determinado grupo humano los que serán tomados como modelos, aunque a veces se recrean animales de los que se ha oído hablar vagamente, pero nunca se han visto. 
El uso simbólico de los animales en Mesoamérica y en la Zona Andina es sumamente amplio, quizá como en todas las culturas no industrializadas del mundo, pues como se ha mencionado, es la forma de encontrar al otro.

De los animales que están plasmados en los tejidos, destacan los felinos cuyo protagonista es el jaguar. Se encuentran en casi todas las culturas amerindias. Éstos se podrían englobar dentro de los animales: cuadrúpedos o de pelo; junto con los que vuelan o de plumas, y los que se arrastran con piel de escamas. En cambio los peces no desempeñaban un papel importante en la cosmovisión mesoamericana y si lo tenían en la Zona Andina, puesto que se creó una gran fuente de riqueza con la pesca, y así lo testifican los textiles.

\section{Felinos}

Jaguar

Simbolizaba la noche y el poder nocturno. Era el animal por excelencia, sobre todo de los chamanes y de los hombres de poder, como los reyes y los sacerdotes. El jaguar, ciertas aves y las serpientes sintetizaban lo más significativo de la naturaleza y de alguna manera cubrían los órdenes más importantes.

El maíz es la semilla vinculada al supramundo. El cacao es la semilla por excelencia vinculada al inframundo; entonces, el cacao está asociado al poder de los gobernantes. El jaguar está vinculado a los hombres del poder (a los del poder del inframundo).

Los jaguares son los que desestructuran, los que crean el caos. Porque este caos es esa otra parte de la realidad; está en el inframundo; es oscuro, salen de la norma.

El jaguar como el gran progenitor "como el padre" está en el fin de los tiempos y en el proceso de renovación siguiente, pues antes se veía así: de manera cíclica. Está en el principio y el final de los tiempos. Es el que reestructura los tiempos.

Makowski et alt. (2006:183) Felino, probable jaguar, pero con cabeza "añadida" (Stone-Miller 1992. To Weave for the Sun... Catálogo Maiman(2006:202) Felinos que tienen la cabeza de frente y una soga que les cuelga del cuello. Muy claras las manchas del cuerpo. Cortez Billet (1998)7 argumenta que en la Cultura Chancay, los felinos son animales totémicos, asociados a las fuerzas de la tierra y al poder. Durante el Periodo Intermedio Tardío, el felino se convirtió en una deidad secundaria, asociada a los dioses principales de este período. Laurencih Minelli (1984:57) felinos que tienen colas enrolladas que recuerdan la serpiente, tejidas a la derecha o a la izquierda alternativamente. Periodo Intermedio Tardío: Costa Centro-Meridional.(1984:70) es el mismo caso. (1984:67) En este caso son 12 felinos de cuerpo manchado, echado y mostrando sus dientes. Época Ica-Inca.

Carlson (2010:12) propone que el felino

"en su apariencia fascinante, muy superior a las propiedades del ser humano, representaba en otros centros de desarrollo Formativo del Perú, a un dios o demonio poderoso con afinidad al agua”.

Queda claro pues que el deseo de fertilidad respecto a plantas, animales y al hombre era su primera preocupación tanto en la Sierra como en la Costa de la Zona Andina en general. Esta preocupación y esperanza a la vez, fueron siempre los elementos fundamentales de su religiosidad. La falta de agua y/o el exceso de lluvias destructoras, siempre se solventaban con oraciones a sus dioses. El culto pues, se expresaba de varias maneras y se reflejaba en la piedra, el metal, y principalmente en los tejidos. Esta es pues la razón que se encuentren fragmentos textiles con las imágenes del felino desde épocas muy tempranas (Garagay, La Galgada, Caballo Muerto), como expresión del culto a la fertilidad (fig.Tejido probablemente Callango) (Fig. 5a). Y a continuación, en Chavín se encuentra su continuidad que no parará hasta los Incas. Veremos la combinación de felino y signo agua/ tierra en textiles tan interesantes como en este del Valle de Santa (fig. Textil y relieve de Recuay) que tiene un claro paralelo en un relieve de piedra (s.I d.C.) del mismo lugar. Son pues representaciones dualísticas, muy frecuentes en la Zona Andina. (Fig. 5b)

\section{Zorro}

\section{Zorro celestial y Plantas Cósmicas.}

Hay una tradición Andina que habla de un zorro con su cría en su boca y un ave. Itier ${ }^{8}$ en su artículo explica que este zorro que viaja al Mundo Superior sobre las alas de un cóndor, para participar en un banquete celestial, proporciona una explicación cosmológica del origen de las cosechas en los Andes. El zorro glotón se comporta tan mal que hace una larga cuerda de ichu hasta que encuentra a los loros. Como que los ridiculiza, los loros empiezan a picotearle la cuerda hasta que se rompe y cae a la tierra. El cuerpo del zorro revienta, esparciendo semillas, raíces y frutos por toda la tierra. Todo esto crece hasta llegar a convertirse en las cosechas de los Andes: cereales, patata y quinoa.

7. Cortez Billet,V. Arte Chancay. Concepción ritual del Mundo. En: Contemporaneidad del Arte Chancay, Lima, COSAPI.

8. Cesar Itier. "El zorro del cielo: Mito sobre el origen de las plantas cultivadas y los intercambios con el mundo sobrenatural”. Bull.IFEA,26,nº 3 . 1997. pp.308-328. 


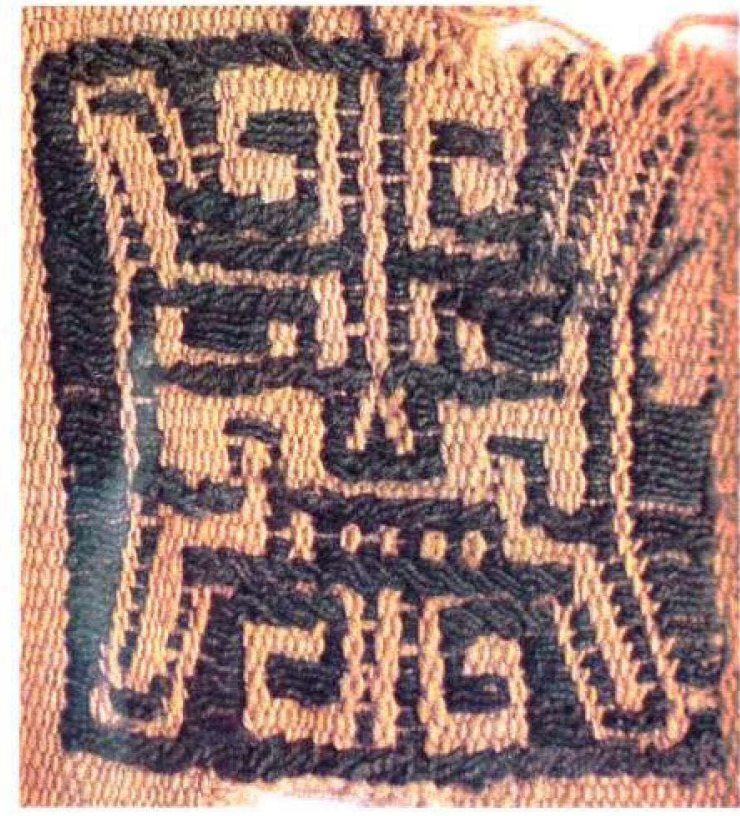

Figura 5a. Tejido probablemente Callango.(Con permiso de U. Carlson 2010: 14).

En Mesoamérica también está profusamente representado tanto en textiles como en los Códices. En el Códice Borgia aparece en forma de personaje vestido con traje ceremonial de jaguar ${ }^{9}$; también en el Códice Cospi, Códice Laud, Códice Fejérvary Mayer y Códice Vaticano B entre otros. En el mundo maya es recurrente, entre la vestimenta de los grandes personajes (príncipes, reyes o sacerdotes), cuando realizaban sus ceremonias. Por lo tanto, este felino era común en el territorio mesoamericano, convivía con otros animales y era relativamente fácil poderlo ver en sus selvas, junto a los ríos, durmiendo de día y atacando de noche.

\section{Aves}

Los pájaros han sido motivos textiles con frecuencia tanto en Mesoamérica como en la Zona Andina. En la primera, están pintados en sus Códices prehispánicos y coloniales principalmente. En la segunda, son tejidos con tanto esmero, que se puede saber muchas veces de qué ave se trata. Formaron siempre parte de su día a día. Y son exclusivamente aves marinas. Sus representaciones se sitúan en ribetes o esquinas de mantos; y también como motivos secundarios en otras representaciones de hombres o animales. (Fig. 6). Y se podría dar el caso de que estas aves eran adoradas porque su presencia prometía una buena pesca (son el indicador
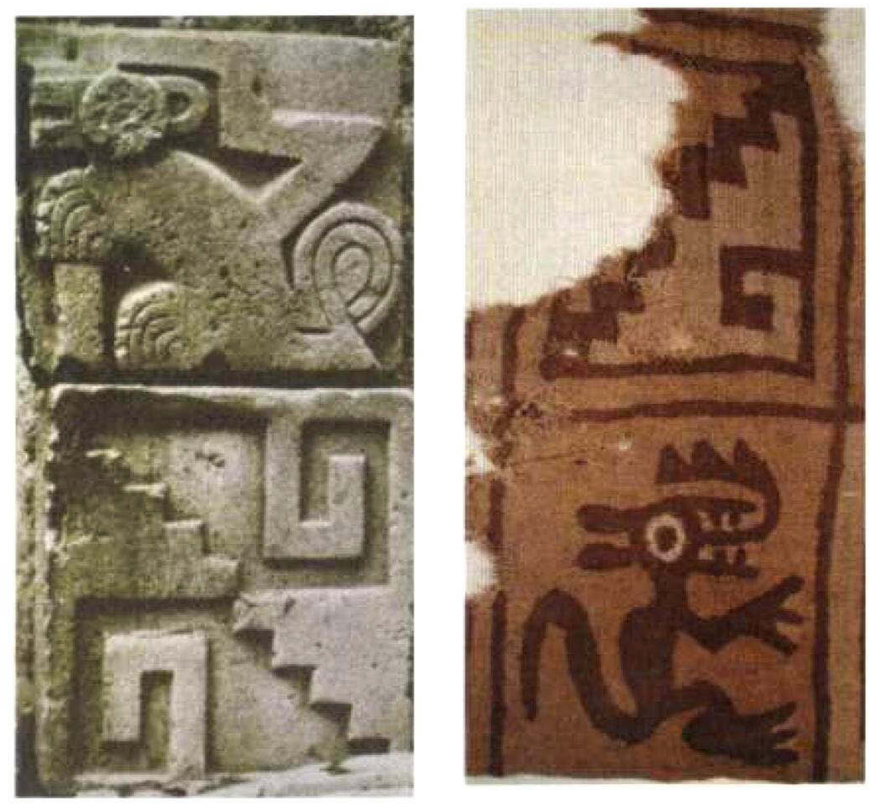

Figura 5b. Relieve de piedra (Recuay) y de tejido pintado (Costa Norte) donde se combinan para indicar los elementos agua y tierra (con permiso de U.Carlson 2010:15).

de la riqueza de la fauna marina). Por lo tanto, si no habían peces tampoco aves. Y por lo tanto, se adoraban para propiciar esta pesca. Por esta razón en textiles donde haya imágenes divinas acompañas de aves, éstas tenían un lugar específico que no era estético sino simbólico. "Eran mensajeras de las divinidades" (Carlson, 2010:43).

La golondrina, el halcón y el cóndor: son aves importantes y muy representadas en los tejidos, debido especialmente a su papel de progenitores en la mitología peruana.

Makowski et alt. (2006:214). Se trata de pelícanos muy frecuentes en la Costa peruana, a punto de volar o aterrizar. Costa Central, estilo local. (2006:116) El pelicano es una deidad secundaria en la Cultura Chimú. A pesar de ello, en este textil es un pelicano real de ancho cuerpo, puesto que lleva colgando del pico un pescado (corvina o un lenguado). Vivian en las islas de guano, era uno de los productores más importantes del mismo, y se usaba como fertilizante.

Laurencich Minelli (1984:51) también se representa un pelícano con algún objeto redondo que no parece un pez, colgando de su pico. (1984:88) en que aparecen cormoranes que son unas aves palmípedas marinas que viven cerca de la costa. Otros estan estilizados (1984:89) y no se puede precisar de qué pájaro se trata. O bien son papagayos, perfectamente tejidos (1984: 97). 


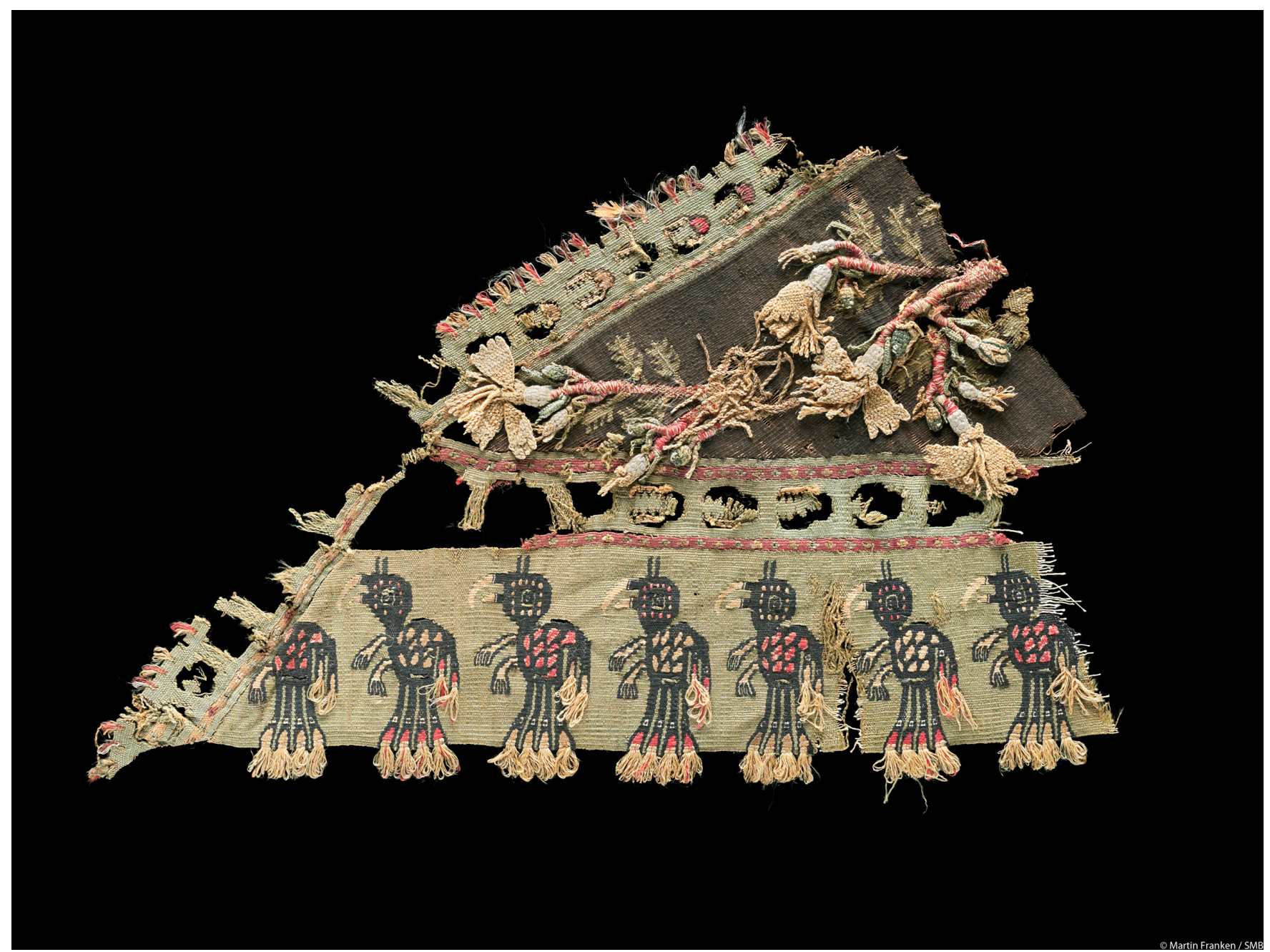

Figura 6. Pájaros (Picaflores). Staatliche Museen zu Berlin, Ethnologisches Museum, V A 58040, fotógrafo: Martin Franken.

\section{Serpientes}

También se encuentran profusamente representadas en ambas zonas: Mesoamérica y Andina. Es el animal terrestre por excelencia y desde los primeros tiempos. Convivían también con ellas y los dibujos de su piel, variados y bellos, les abrían nuevos campos de expresión artística como tejerlos en sus textiles, de uso diario, funerario o ceremonial.

En Mesoamérica, fue el que tuvo más complejidad de símbolos. Ya se encuentran fragmentos de textiles en la Cueva de la Candelaria, Coahuila, en los que se ha representado los dibujos de su piel ${ }^{10}$, pasando por Teotihuacan, donde simboliza el poder político, y también en el mundo Maya, donde por ejemplo, en Chichén Itzá está plasmada en sus muros $^{11}$, con una precisión extraordinaria. Y finalmente en los Códices, donde aparece la serpiente de cascabel (Crotalus sp) dibujada en los trajes de algunos de sus dioses. Ejemplo de ello, es la falda de Coatlicue. Y ya no digamos en Quetzalcóatl, la serpiente emplumada.

En la Zona Andina, también es frecuente que adorne ciertos tejidos desde los comienzos de su historia, hasta el final. Está representada en todas las épocas. Dobles serpientes en Makowski et alt._(2006:122-124). Es una S vertical que termina con dos cabezas de serpiente. Afirman que este motivo iconográfico está muy bien documentado en otros textiles de la Costa Sur. Frame (1984) dice que la iconografía de la serpiente en los tejidos, produce imágenes lineales y flexibles. En este caso, las serpientes con doble cabeza derivan de la estructura del tejido retorcido. Laurencich Minelli (1984:74/ 1984:76-77) muestra serpientes de doble cabeza en un textil 
del Periodo Intermedio Temprano y otros del Intermedio Tardío (Costa Central Perú) respectivamente. En estos textiles aparecen en sentido vertical (S), alternando sus colores.

\section{Simbolo de la "s" vertical}

Makowski et alt. (2006:188), La S del borde (banda) de la tela puede ser una repetición del mismo motivo de manera simplificada, o puede referirse a otro motivo generalizado desde el Período Pre-cerámico, el de la serpiente de dos cabezas con un cuerpo en forma de $\mathrm{S}$.

\section{Flores y plantas}

Sahagún (1982) afirma que los pueblos prehispánicos desarrollaron sus culturas en estrecho contacto con la naturaleza. De la flora y la fauna obtenían su alimento, vestido y curación. Y además muchos animales y plantas tenían valor y significado mítico-religioso.

Lot (1983) cita toda una serie de autores que interpretaron representaciones botánicas en documentos antiguos y en el arte $^{12}$. Se han encontrado el nopal, las flores de maguey, biznagas, todas ellas cactáceas. También el Dondiego de día, lirio de agua (nenúfar), atlacuetzon (flor de yerba de agua) como flores. Y plantas de calabaza, plantas de maíz y mazorcas y planta del cacao. Luna (1996: 38) "Las representaciones de flores o plantas tenían como propósito esencial evocar conceptos como fertilidad, lo sagrado. Muchos elementos fitomorfos fueron plasmados en calidad de signos o glifos".

González Torres (2001) afirma que los indígenas mesoamericanos por su cercanía con la naturaleza, han incluido al mundo vegetal y al animal como símbolo de principios y fuerzas cósmicas y como receptáculo de potencias divinas, dotaron a plantas y animales de poderes sobrenaturales e integraron en un cosmos viviente, en cuyo centro estaba el hombre.

Mesoamérica. Cueva del Buen Abrigo, Coahuila. Hay una pequeña blusa de niño que muestra en su parte frontal dos grandes flores (una a cada lado) pintadas, sobre un textil de tafetán. (Filloy 2017:33).Hay también muchas ilustraciones sobre flores en los códices (Codice Duran, cap.XVI, pág.152, párrafo 6).

Dupey (2015 : 53 ) afirma: "En los códices Borgia y Cospi, el perfume intenso que se desprende de las guirnaldas y coronas de flores se plasmó mediante el añadido de una o dos flores esquemáticas sobre estos adornos". Una o varias flores aparecen a veces coronando los platos llenos de comida y los recipientes que contienen bebidas como el cacao, así como rematando corazones, espinas y punzones ensangrentados. Por ello, cree que es posible que hayan simbolizado lo precioso, pues la flor encarnaba esta idea en varios aspectos de las culturas prehispánicas.

Vela (2006:46-47) afirma que pocos dioses en el panteón prehispánico no tienen asociación con las flores; algunos tenían una relación más estrecha y de hecho eran sus patronos. Xochipilli, "príncipe de las flores” era el dios de la danza, los juegos, las flores y el amor. Estaba asociado con la Tierra, la fertilidad y la vida. Al mismo tiempo, se le relacionaba con el Sol naciente, la procreación y el placer. Junto con Xochiquétzal, era quien permitía la germinación de las plantas y creador de las flores. Macuilxóchitl, “cinco flor" Su nombre hace alusión a una fecha del calendario. Es una advocación de Xochipilli y muchas veces se le atribuye la misma identidad. Dios de las flores, el juego, el canto y la música, también era patrón de los nobles. Es considerado el dios principal de los ahuiateteo, los cinco dioses asociados con el exceso, el placer y su respectivo castigo. Xochiquétzal, "plumas de quetzal florido”, "flor-quetzal" Era considerada la diosa madre joven y estaba relacionada con el placer, el amor y las flores. Era patrona de las tejedoras y de las artes que practicaban las mujeres nobles, del amor sexual, los quehaceres domésticos y las prostitutas; también protegía a los recién nacidos y a las madres embarazadas.

Velasco y Nagao (2006:29) afirman:

"En las sociedades prehispánicas, las flores ofrecen un amplio panorama de significados, que fueron adaptados a las diversas cualidades de las diferentes especies. Las antiguas representaciones de las flores, en gran variedad de materiales, no eran solamente decorativas, sino que formaban parte de un simbolismo basado en el respeto y la preocupación por el bienestar de los dioses, que se manifestaba en los elementos de la naturaleza.”

Las plantas y las flores han estado presentes en diversos periodos y culturas de Mesoamérica. Del Preclásico, hay representaciones de maíz y de brotes de vegetación en hachas olmecas de piedra verde y en relieves en las rocas de Chalcatzingo, Morelos. En las estelas de Izapa, Chiapas, se ven árboles, algunos dando frutos, en escenas que aparecen en la epopeya del Popol Vuh, obra de un periodo posterior.

En el Clásico proliferaron las imágenes de flores en varios contextos y con una mayor diversidad de connotaciones. Heyden escribió que la flor tetrapétala ha tenido un significado polifacético en las culturas antiguas y actuales de 


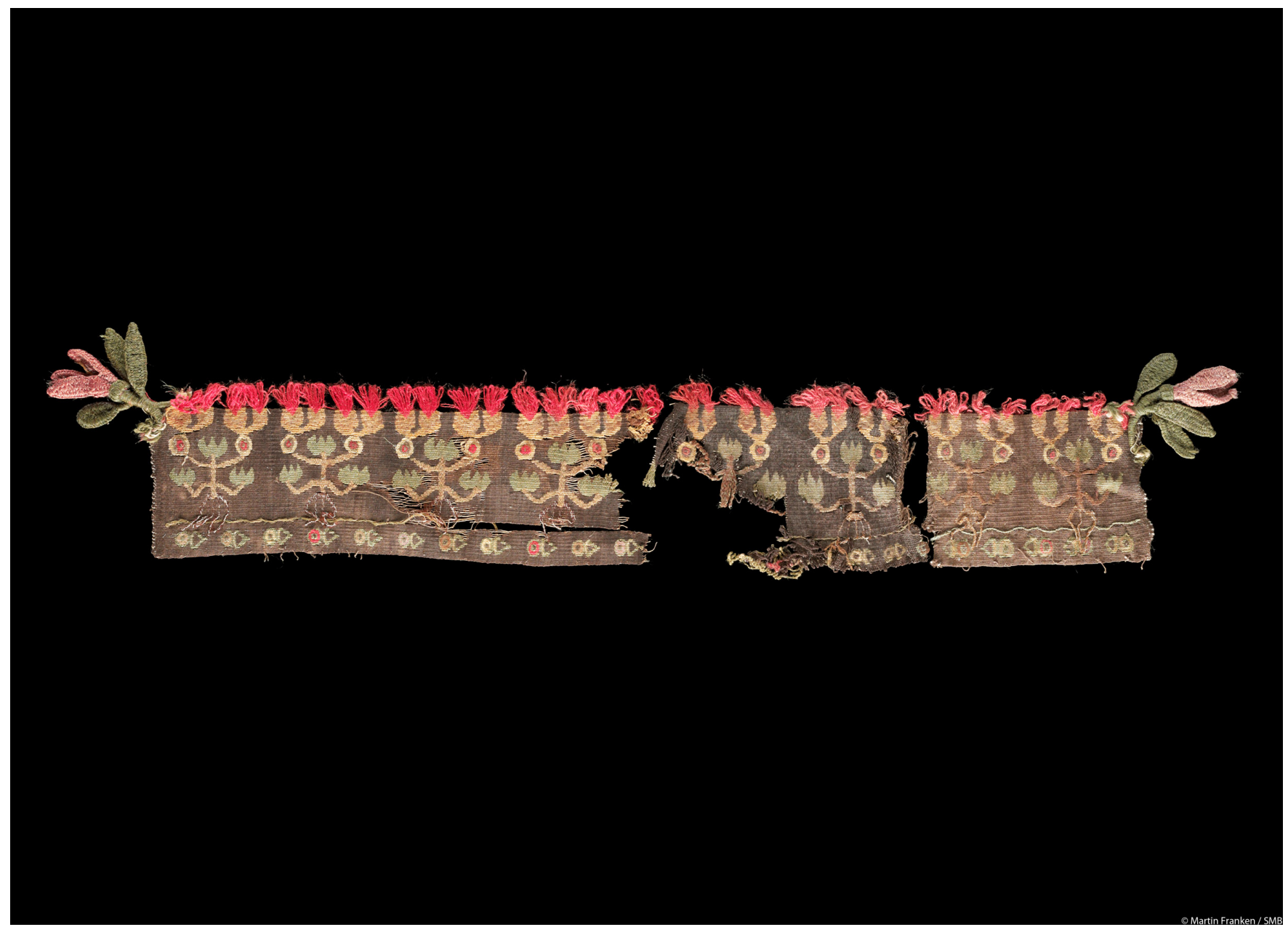

Figura 7. Textiles Lambayeque. Plantas. Staatliche Museen zu Berlin, Ethnologisches Museum, V A 58026, fotógrafo: Martin Franken.

Mesoamérica, y que es uno de los símbolos persistentes en la mente y en el lenguaje de sus habitantes. Hay numerosas representaciones de flores de cuatro pétalos en Teotihuacan, estado de México: en la arquitectura, esculpidas en la Subestructura de los Caracoles Emplumados; grabadas en las vasijas trípodes de barro; moldeadas en los adornos adheridos a los incensarios, o como tocado de figurillas de barro. De acuerdo con Heyden, esta flor aparece con tanta persistencia en Teotihuacan coronando algunas figurillas, que es probable que tenga un sentido dinástico. Heyden asoció este simbolismo con la cueva que se encuentra bajo la Pirámide del Sol, en Teotihuacan, la cual fue modificada para darle forma de flor y que posiblemente funcionó como lugar sacro, oráculo, punto de llegada de peregrinos, y es uno de los símbolos fundacionales de sitios sagrados y ciudades.

Las flores teotihuacanas también formaron parte de la iconografía de la pintura mural, a veces aludiendo a un lugar paradisíaco (como en el Tlalocan de Tepantitla), otras veces refiriéndose al canto y a lo bello de las palabras
- simbolizado en las vírgulas floridas que salen de la boca de diversos personajes - y como arbustos en plena flor como motivos centrales (en Techinantitla), tal vez en alusión a topónimos o a linajes.

En el caso de la Zona Andina también podemos decir que es muy frecuente encontrar flores plasmadas en sus textiles, en culturas principalmente de la Costa, como la Nazca. En sus mantos aparecen flores, claramente tejidas en líneas diagonales.

De la Cultura Lambayeque, hay una gran colección de textiles en el Museo Etnológico de Berlín que han sido recientemente publicados y que muestran la riqueza vegetal de aquella zona, plasmada en sus tejidos. (Bjerregaard,L 2017: 104/109-111). Se pueden ver plantas del algodón (V A 57033); personajes cuidando su jardín (V A 62275); todo tipo de plantas y de flores en esta colección que perteneció a Wilhelm Gretzer (V A 58040 a,b,c; V A 58026; V A 58018; V A 58021; V A 58028), viva presencia textil de los vegetales que representan. (Fig. 7) 


\section{Conclusiones}

Con este estudio que pretende tener continuidad, se quiere poner de relieve toda una serie de imágenes tejidas en los textiles de las dos grandes zonas habitadas de Amerindia, como son: Mesoamérica y la Zona Andina, que se repiten en ambas, con el mismo significado, a los que llamaremos signos comunes.

En este primer intento, se han escogido: el meandro escalonado/ Xicalcoliuhqui; la S horizontal /nube/ grecas en espiral. De entre los animales: el felino (jaguar y zorro), aves y serpientes. Y finalmente, flores y plantas. De esta manera se cubre un panorama bastante completo de la vida de los antiguos pobladores de estas dos zonas.

Y sin grandes sorpresas, puesto que el tema de la fecundidad ya está imbricado desde un buen principio, en el día a día de estas personas que tenían como base económica, la agricultura, y los animales, surge la FECUNDIDAD como eje de todos estos signos. Ellos la propiciaban y por esta razón está en todos sus actos sagrados, y en sus vidas diarias. Era el eje de la relación hombre/dioses desde un buen comienzo.

Todo este tema queda claro desde el comienzo del estudio y también que en cada lugar según sus circunstancias geográficas y climáticas, coincidan estos signos.

Es por lo tanto una contribución a la idea de que estas dos zonas se relacionaron en épocas parecidas, porque tenían que cubrir las mismas necesidades para poder vivir con una cierta comodidad, a pesar de que en Amerindia, en general, todo fue muy difícil de conseguir puesto que sus medios fueron limitados pero su inteligencia y voluntad consiguió grandes logros.

Y en el caso que nos ocupa, fueron los textiles, espejo de sus vidas y creencias, los que nos muestran estos signos comunes.

\section{Bibliografia}

BEYER, H (1924), El origen, desarrollo y significado de la greca escalonada, El México antiguo tomo 2, México. pp. 248.

BJERREGAARD, L (2017) Pre-Columbian Textiles in the Ethnological Museum in Berlin. Zea Books. Lincoln, Nebraska. https://digitalcommons.unl.edu/zeabook/52

CARLSON, U. (2010) Iconografía Andina. Interpretación del simbolismo en antiguos tejidos peruanos. Braunschweig.

CARLSON, U. (2014) El simbolismo de la iconografía emblemática Mochica. Braunschweig.

CASO, A (1992). “Reyes y Reinos de la Mixteca”. FCE, México 1992. pp. 246.
CODICE DE MADRID (1970) Codex Tro-Cortesiano. Codices Selecti. Vol. VIII. ADEVA, Graz, Austria.

CODIGO MAGLIABECCHIANO (1970) Intro y Sumario por F. Anders. CL XIII,3 (B.R. 232) Biblioteca Nazionale Centrale di Firenze. ADEVA, Graz, Austria.

DUPEY GARCIA, E. (2015) “De vírgulas, serpientes y flores. Iconografía del olor en los códices del Centro de México", Arqueología Mexicana núm. 135, pp. 50-55.

DUPIECH CAVALERI, D. (2016), Los textiles mayas contemporáneos de Yucatán en el espejo del Códice Trocortesiano. Anales del Museo de América, XXIV, pp.169-210.

FILLOY, L. (2017) Mesoamerican Archaeological Textiles: An Overview of Materials, Techniques and Contexts. En Jornadas de Textiles PreColombinos VII, Zea Books, Lincoln, Nebraska. pp.7-39. https://digitalcommons.unl.edu/pct7/3

GONZALEZ TORRES, Y, (coord.) (2001) Animales y plantas en la Cosmovisión Mesoamericana.

México, CNCA, INAH, Plaza y Valdés, ECN, vol. 33, 2002, pp. $375^{-}$ 389 (en colaboración con Martha Ilia Nájera).

HEYDEN, D.(1985) Mitología y simbolismo de la flora en el México prehispánico. UNAM. México. 176pp.

HUCKERT, CH. (2006) Representaciones textiles del México Precolombino: Variaciones en torno al motivo de Xicalcoliuhqui, en Actas III Jornadas Internacionales sobre Textiles Precolombinos, Victòria Solanilla (ed.), Barcelona, pp.111-128.

KERR, Justin, (1989) The Maya Vase Book. A Corpus of Rollout Photographs of Maya Vases, Volume 1. Nueva York: Kerr Associates 1989/1990/1992/1995/1997/2000

LAPINER, A.(1976) Pre-Columbian Art of South America. Abrams, New York

LAURENCICH MINELLI, L. (1984) Antichi tessuti Peruviani. Electa Editrice. Milano.

LOT, A y MIRANDA, G.M. (1983)," Nota sobre las interpretaciones botánicas de las plantas acuáticas representadas en los códices mexicanos", en Imágenes de flora y fauna en culturas precolombinas: iconografía y función. J.F. Petreson, ed. BAR International Series, England. 171:85-92.

LUNA, A. (1996) La flora representada en la iconografía pictórica, en "Pintura mural prehispánica" Estudios, t.II, pp. 37- 39. Bol. Informativo. Año $2, \mathrm{n}^{\circ} 5$, diciembre.

MAKOWSKI,K, ROSENZWEIG, A \& JIMÉNEZ DÍAZ,M.J. (2006). Weawing for the Afterlife, Peruvian Textiles from the Maiman Collection. Herzliya: Ampal/Merhav.

MEIGHAN, C. W. (1969) Cultural Similarities Between Western Mexico and Andean Regions. En Pre-Columbian Contact Within Nuclear America, edited by J. C. Kelley and C. L. Riley, pp. 1 1-25. Mesoamerican Studies No.4. University Museum, Southern Illinois University, Carbondale.

MONTOYA, J (2008) Los tejidos mayas. Espejos de una cosmovisión. Etnografisch Museum-Fundació Caixa de Girona. Cholsamaj. Guatemala. 
MORALES DAMIÁN, M.A. (2009) Tejer en el árbol florido. Análisis comparativo de la lámina de Atamalcualiztli, Primeros memoriales y las imágenes de las deidades tejedoras en el Códice Madrid, en Actas IV Jornadas Internacionales sobre Textiles Precolombinos, Victòria Solanilla (ed.) Barcelona, pp. 97-108.

PRIMEROS MEMORIALES (1993). Ed. facsimilar. F. Anders (fotos) University of Oklahoma Press, Norman.

RIEFF ANAWALT, P. (1992) Archaeology Ancient Cultural Contacts between Ecuador, West Mexico, and the American Southwest:Clothing Similarities, Latin American Antiquity, Vol. 3, No. 2 (Jun., 1992), pp. 114-129.
SAHAGÚN. F.D. de (1982) Historia General de las Cosas de Nueva España. Porrúa. México.

SCHELE,L. \& MILLER, M.E. (1992) The Blood of Kimgs: Dynasty and Ritual in Maya Art. Londres. Thames and Hudson.

SWADESH, M. (1967) Lexicostatistic Classification. en Linguistics, editado por N. A. McQuown, pp. 79-115. Handbook of Middle American Indians, vol. 5, R. Wauchope, general editor. University of Texas Press, Austin

VELA, E. (2006) “Los antiguos dioses y las flores”, Arqueología Mexicana 78, pp. 46-47.

VELASCO, A.M. y NAGAO, D (2006), Mitología y simbolismo de las flores, Arqueologia Mexicana 78, pp.28-35

Victòria Solanilla

Octubre 2019 